\title{
Graham A. Runnals, Les mystères dans les provinces françaises (en Savoie et en Poitou, à Amiens et à Reims)
}

\section{Antonella Amatuzzi}

\section{(2) OpenEdition}

12 Journals

\section{Edizione digitale}

URL: http://journals.openedition.org/studifrancesi/35798

DOI: 10.4000/studifrancesi.35798

ISSN: 2421-5856

\section{Editore}

Rosenberg \& Sellier

\section{Edizione cartacea}

Data di pubblicazione: 1 juillet 2005

Paginazione: 139-140

ISSN: 0039-2944

Notizia bibliografica digitale

Antonella Amatuzzi, «Graham A. Runnals, Les mystères dans les provinces françaises (en Savoie et en Poitou, à Amiens et à Reims)», Studi Francesi [Online], 145 (XLIX | I) | 2005, online dal 30 novembre 2015, consultato il 19 avril 2021. URL: http://journals.openedition.org/studifrancesi/35798 ; DOI: https:// doi.org/10.4000/studifrancesi.35798

Questo documento è stato generato automaticamente il 19 avril 2021.

\section{(c) $(1) \odot$}

Studi Francesi è distribuita con Licenza Creative Commons Attribuzione - Non commerciale - Non opere derivate 4.0 Internazionale. 


\title{
Graham A. Runnals, Les mystères dans les provinces françaises (en Savoie et en Poitou, à Amiens et à Reims)
}

\author{
Antonella Amatuzzi
}

\section{NOTIZIA}

GRAHAM A. RUNNALS, Les mystères dans les provinces françaises (en Savoie et en Poitou, à Amiens et à Reims), Paris, Champion («Bibliothèque du XVe siècle»), 2003, pp. 311.

1 Partendo da una prospettiva non strettamente letteraria ma considerando piuttosto $\mathrm{i}$ «mystères» come spettacoli ed avvenimenti storici, e basandosi quindi su documenti d'archivio, libri di conti, contratti, memorie e cronache, Graham Runnals riunisce in questo volume sei studi che illustrano la fecondità e la varietà dell'attività teatrale alla fine del Medio Evo in alcune province francesi (o meglio francofone).

2 Il primo, Les mystères savoyards perdus et retrouvés (pp. 15-32), fornisce la descrizione e l'analisi di alcuni documenti appartenuti al farmacista savoiardo, appassionato di arte e letteratura, Florimond Truchet (1842-1916), che solo recentemente sono stati ritrovati e di cui le Archives départementales de la Savoie possiedono i microfilm. Si tratta di:

- quattro rimaneggiamenti di diverse giornate del Mystère de l'Antéchrist et du Jugement de Dieu che vengono confrontati con altri manoscritti conservati alla BNF e alle Archives départementales de la Savoie. Si hanno cosi tracce di due, o forse tre, versioni del testo rappresentato almeno due volte a Modane (1580 e 1606);

4 - un manoscritto de La Dioclétiane, tragedia che mette in scena il martirio di San Sebastiano, di cui si annuncia un'edizione a cura di Gaston Tuaillon;

- un manoscritto che contiene dei frammenti del Mystère de Saint Sébastien; 
6 avvenuta a Saint-Jean nel 1573, che viene pubblicato nel terzo studio (Le 'Registre' du 'Mystère de la Passion' joué à Saint-Jean-de-Morienne en 1573, pp. 127-89); environnantes (pp. 191-225), offre un panorama generale delle rappresentazioni dei «mystères» a Poitiers e nelle città limitrofe. Come fonte di informazione l'A. fa ricorso, tra l'altro, al poeta, 'chroniqueur' e 'rhétoriqueur' Jean Bouchet. La conclusione è che, sebbene le conoscenze sul teatro medievale in Poitou siano lacunose, le varie allusioni, descrizioni e documenti analizzati dimostrano che «la vie théâtrale en Poitou ressemblait à celle de toutes les autres régions francophones, à la fois par les textes joués [...], par l'envergure des spectacles [...] et par la participation de la communauté tout entière, surtout la ville de Poitiers» (p. 207).

11 Il quinto, La 'Passion' d'Amiens de 1500 (pp. 227-63), si occupa della Passion recitata ad Amiens nel 1560. Dall'esame di documenti conservati alle Archives Municipales di Amiens (che l'A. trascrive in appendice) risulta che il testo della Passion e quelli dei «sécrés», gli effetti scenici più impressionanti, furono presi in prestito dalla città di Mons l'anno successivo. Si ha quindi la prova che la Passion di Mons è largamente debitrice di quella di Amiens, inspiegabilmente meno conosciuta e meno studiata.

L'ultimo contributo, La 'Passion' de Reims de 1490, les 'Mémoires' de Jean Foulquart et Guillaume Coquillart (pp. 265-90), concerne la Passion messa in scena a Reims nel $1490 \mathrm{di}$ cui nessuna traccia è rimasta negli archivi contemporanei. Vengono confrontate le diverse versioni dei Mémoires di Jean Foulquart, procuratore di Reims, che contengono la descrizione di questa rappresentazione, inserite in appendice. Se ne ricavano notizie interessanti, seppur lacunose, sul testo stesso, sulle date e la durata dello spettacolo, sulle responsabilità di Foulquart nello spettacolo. 